\title{
De pro Franquista a anti Gobierno. La evolución de Sur con respecto a la política nacional durante la transición española $(1975-1978)^{1}$
}

\author{
Jezabel MARTínez FÁBREGAS \\ Universidad de Sevilla \\ jmartinez10@us.es
}

Recibido: 03-03-2015

Aceptado: 11-09-2015

\section{Resumen}

La transición española, el proceso político por el cual España dejó de ser una dictadura para pasar a ser una democracia, vino acompañada de la disolución del Movimiento Nacional en abril de 1977, soporte institucional de la cadena de Prensa del Movimiento desde sus inicios. Este hecho, entre otros, contribuyó a que /Sur/, diario de referencia regional de la cadena en Andalucía, evolucionara tanto estructural como ideológicamente para adaptarse al nuevo régimen político.

El presente estudio, a través del análisis de contenido aplicado a editoriales, artículos y columnas de opinión publicados por el diario entre 1975 y 1978, explora el proceso por el cual la cabecera regional editada en Málaga abandonó su función propagandística con respecto al Gobierno, considerándolo antidemocrático, y apoyó al PSOE, presentándolo como la mejor alternativa a la UCD al frente del estado español, habiendo asumido así su rol como agente político.

Palabras clave: comunicación política; historia de la comunicación: prensa franquista; prensa del movimiento; transición española; propaganda.

\section{From Pro-Franco to Anti-Government. The Evolution of the Sur regarding National Politics during the Spanish Transition (1975-1978)}

\begin{abstract}
The Spanish transition, the political process through which Spain ceased to be a dictatorship to become a democracy, was accompanied by the dissolution of the National Movement, the institutional support for the chain of the Movement Press from its beginnings, in April 1977. This fact, among others, contributed to the /Sur/, the regional reference newspaper for the chain in Andalusia, evolving both structurally and ideologically to adapt itself to the new political regime.

This study applies content analysis to editorials, articles and columns published by the newspaper between
\end{abstract}

${ }^{1}$ Este trabajo presenta parte de los resultados de la tesis doctoral de Martínez Fábregas, Jezabel. 2014. La imagen del Gobierno en la prensa oficial durante la transición española (1975-1978). Análisis comparativo de Arriba, Pueblo, Solidaridad Nacional, El Pueblo Gallego, Hierro, Sur y Odiel, incluida en el proyecto de investigación: "El papel de la prensa diaria en la transición democrática. Cobertura informativa y comportamiento político de diarios y periodistas", referencia CSO 2012-36774, financiado por el Plan Nacional de I+D 20122015, dirigido por el Catedrático Jaume Guillamet i Lloveras (Universitat Pompeu Fabra de Barcelona, España). 
1975 and 1978, exploring the process through which the regional newspaper edited in Málaga abandoned its propaganda function with regard to the Government, considering it undemocratic, and supported the PSOE, presenting it as the best alternative to the UCD in the Spanish Executive, thus taking on its role as a political agent.

Key words: political communication; communication history; Francoist press; movement press; Spanish transition; propaganda.

\section{Referencia normalizada}

Martínez Fábregas J. (2016): "De pro Franquista a anti Gobierno. La evolución de Sur con respect a la política nacional durante la transición española”, Política y Sociedad, 53 (2), pp. 485-507.

Sumario: 1. Introducción y estado de la cuestión. 2. Metodología. 3. Resultados y Discusión. 4. Conclusiones. 5. Bibliografía.

\section{Introducción y estado de la cuestión}

La dictadura franquista se esmeró en erigir diferentes pilares sobre los que legitimar el régimen: a) el carisma del Caudillo (Zugasti, 2005); el Movimiento Nacional, sobre el que se instituyó toda su política autocrática (Payne, 1997); y la cadena de prensa del movimiento, vehículo de expresión para la propaganda franquista (Zalbidea, 1996), entre otros.

Sin embargo, este clima de estabilidad política construido para la perpetuación del régimen franquista tocó a su fin con la muerte de Franco en 1975, que supuso el inicio de la desintegración de la coalición franquista que había reinado en España durante la dictadura, y la consecuente transición (Maravall y Santamaria, 1984:114). Un proceso que llevó a España a alcanzar el status democrático en todos los niveles (Guillamet, 2002: 595). Sin embargo, por centrarse este trabajo en el comportamiento del diario oficial Sur con respecto al Gobierno durante la transición española, nos hemos centrado en la transición ocurrida en los niveles político y periodístico. Si atendemos a cada uno de estos factores, podemos decir que los límites temporales de la transición varían según el objeto de estudio (Meneses, 2008: 93).

A nivel político, la mayoría de autores consultados coincide en señalar la muerte de Franco, el 20 de noviembre de 1975, como punto de inicio de la transición española, aunque difieren en su punto final. Para Soto (1994: 110-111), el proceso concluyó con la victoria del PSOE en las elecciones generales de 1982; por su parte, Fusi (1997: 44) defiende que el punto final de la transición política es 1986, cuando España consiguió entrar como miembro conformante de la Comisión Económica Europea (CEE). Guillamet (2002: 132), sin embargo, asevera que fue en diciembre de 1978, con el referéndum de la Constitución, cuando la transición concluyó, ya que la Carta Magna trajo consigo las bases legislativas que permitieron al país emprender su rodaje democrático y constitucional.

Este profundo debate también se extiende a la prensa. Mientras para Barrera, ésta comienza su transición en 1966, con la ley Fraga, que bajo la apariencia de liberal imponía cautelas para seguir controlando a la prensa (1995: 154), para Meneses (2008: 83-84), lo hace en 1975, con la muerte de Franco. Y, mientras para el primero, el fin de la transición periodística se produce en 1978 con las garantías constitucionales que en 
materia de información provee la Carta Magna, para Meneses (2008: 83-84), el cese de represalias contra los periodistas a partir de 1982 pone punto y final a la transición en la prensa.

Tomando en consideración este profundo debate, para la acotación de nuestro periodo de estudio hemos optado por seguir el límite temporal propuesto por el profesor Guillamet (2002: 132), siguiendo así la línea del proyecto de investigación en el que se enmarca este trabajo: desde la muerte de Franco (20/11/1975) hasta el referéndum de la Constitución (06/12/1978). Entendemos por tanto que, durante este período histórico compuesto por 38 meses, se producen los cambios a nivel legislativo que conllevan la transición, tanto a nivel político como periodístico (Soto, 1994: 110111). Es decir, el período en el que se sientan las bases para una política democrática y un periodismo libre, garantizados ambos por la Carta Magna, si bien es cierto que el engranaje constitucional tardaría aún unos años en funcionar debidamente, tanto en la política como en el periodismo (Tussel, 1991: 10-11; Meneses, 2008: 77).

Definido el marco temporal de esta investigación, para estudiar la evolución de la prensa oficial regional con respecto a la política nacional española durante la transición, hemos seleccionado el diario de referencia para la Cadena de Prensa del Movimiento en Andalucía: Sur. Éste fue fundado el 7 de marzo de 1937 como órgano de propaganda del franquismo y, siendo propiedad de Falange Española durante la dictadura, lució el yugo y las flechas en su cabecera hasta la muerte de Franco, cuando los retiró definitivamente, a diferencia del resto de diarios de la cadena, que esperaron al 22 de abril para hacerlo (Martínez Fábregas, 2014: 135). El 22 de abril de 1977, en cumplimiento de la ley 1/1977 de 1 de abril, por la que se disolvía el Movimiento Nacional, el periódico fue incorporado a los Medios de Comunicación Social del Estado, siendo parte de la cadena de prensa estatal hasta 1979, cuando la orden ministerial 1434/79, de 16 de junio de 1979, decretó el cierre de todos los diarios oficiales. Desde entonces, los periódicos estatales comenzaron a cerrar, tras no encontrar comprador en subasta pública (Montabes Pereira, 1989; Zalbidea Bengoa, 1996).

Sur fue una excepción. Previendo ya en 1975 que, con la caída del franquismo, su cierre estaba cercano, puso en marcha una estrategia de supervivencia para mantenerse a flote dentro del competitivo mercado periodístico existente en el país durante ese período. El primer paso fue la retirada de su cabecera del yugo y las flechas de Falange el día 21 de noviembre de 1975; es decir el día siguiente a la muerte de Franco. Con esto, la cabecera malagueña intentaba alejarse de su pasado propagandístico. Y lo hizo. Desde entonces, aumentó su tirada, lo que le permitió ser considerado en 1976 como económicamente rentable (Ruiz Romero, 1998). De difusión regional, a pesar de sólo llegar a cuatro provincias (Córdoba, Cádiz, Málaga y Sevilla), tiraba 22.589 ejemplares diarios (Montabes Pereira, 1989).

El segundo paso de este plan de adaptación le llevó a contactar con empresarios locales para gestionar la inyección de capital en el periódico. La mayoría de ellos (hombres de negocios) empezaron a escribir para este periódico durante la transición. Este plan de renovación dio sus frutos el 5 de mayo de 1984, cuando la Sociedad de Empresarios engendrada dentro del mismo diario compró la cabecera en subasta pública. Seis años 
después, en 1990, el Grupo Vocento se convirtió en socio mayoritario del periódico, siendo desde entonces incluido en las publicaciones de este grupo (Palacio, 2006: 430).

Por lo tanto, considerando que este diario oficial perdió su soporte institucional en abril de 1977, y que emprendió un proceso de reestructuración que le ha llevado a pervivir hasta nuestros días, esta investigación asume que la cabecera malagueña evolucionó ideológica y estructuralmente durante la transición para asegurar su pervivencia. Y, pretende, por tanto, su desmitificación como órgano de propaganda del gobierno durante la transición.

Idea que contrasta con las teorías que, durante las últimas tres décadas, han mantenido autores como Montabes Pereira (en Tuñón de Lara, 1986: 116), quien destaca que la prensa oficial mantuvo su función propagandística durante la transición. En la misma línea, Alférez (1986: 142) sostiene que la prensa oficial se esmeró en ser el altavoz del Gobierno durante el cambio de régimen, o al menos, durante el turno de Arias (Redero y García, 1991-1992: 92). Por tanto, de las afirmaciones anteriores, se entiende que la prensa oficial mantuvo su discurso unificado y favorable al Ejecutivo durante la transición, tal y como era previsible siendo un órgano de propaganda (Postoutenko, 2010; Jackall, 2011), ya que en este tipo de medios no se contemplan posiciones críticas contra la gestión llevada a cabo por la administración (Pineda, 2006).

Por el contrario, Peña Marín (1980: 14) reconoce que, ya durante la dictadura hubo voces de periodistas que, en revistas al servicio del poder, como El Escorial (dirigida por Laín Entralgo y Dionisio Ridruejo), criticaron al poder franquista. Y al igual que ocurriera durante el propio régimen, Meneses (2008: 45) afirma que la prensa oficial acogió diferentes ideologías en sus filas durante la transición. Castro Torres (2010: 145) va incluso más allá, afirmando que las diferentes ideologías que concurrían en la prensa oficial durante el cambio de régimen fueron reflejadas en los discursos sobre la realidad política existente en el país publicados en ella. En esta línea, en los casos concretos de Arriba y Odiel (de difusión nacional y local, respectivamente), ya se ha demostrado que abandonaron su función propagandística con respecto al Gobierno de la transición y asumieron su rol como agente político (Martínez Fábregas y Romero Domínguez, 2014; Martínez Fábregas, 2015).

De esta aparente contradicción y tomando como base los últimos hallazgos en cuanto al verdadero proceder de la prensa oficial con respecto al Gobierno durante la transición, surge nuestra pregunta de investigación: ¿Mantuvo el diario Sur su función propagandística al servicio del gobierno durante la transición a la democracia?

Contestando a esta pregunta, pretendemos alcanzar los siguientes objetivos:

- Probar la presencia de diferentes ideologías dentro de Sur, las cuales se tradujeron en pluralidad discursiva con respecto a la gestión del Gobierno durante la transición.

- Demostrar que Sur asumió su rol como agente político, a través del abandono de su función propagandística durante la transición española.

Para alcanzar estos objetivos, planteamos las siguientes hipótesis construidas según el método hipotético deductivo: 
(H1): Sur acogió diferentes ideologías dentro de su redacción durante la transición. Esta diversidad de pensamiento se tradujo en pluralidad discursiva y de opinión con respecto a la gestión que el Ejecutivo hizo de la transición española.

(H2): Esta variedad de opinión, unida al intento de la cabecera por adaptarse al nuevo panorama periodístico, llevó al periódico a abandonar su función propagandística, asumiendo así su rol de agente político.

Una vez introducida nuestra investigación, procedemos a explicar el método aplicado para hacer frente a esta investigación.

\section{Metodología}

Para abordar la fase de estudio concerniente a la evolución estructural e ideológica del periódico regional, hemos aplicado la biografía técnica propuesta por Casasús (1985: 65). La ficha de análisis técnico diseñada para este estudio, que ha sido reelaborada sobre la que presentó el profesor Mauri en su tesis doctoral (2010: 85-89), consta de dos partes bien diferenciadas: a) los datos registrales y administrativos, que recogen la evolución estructural de la cabecera (lenguas usadas en la redacción, evolución de la tirada y del precio, incidencias, suspensiones o multas sufridas durante su existencia y la ubicación de sus talleres), y b) los datos formales y de contenido, que refieren el formato de la publicación, técnicas de impresión, agencias de información con las que contaba para elaborar las noticias, la composición del consejo de redacción, así como la ideología de sus integrantes. Para identificar su ideología, se ha accedido al catálogo de periodistas elaborado por de López Zuazo (1981), así como a los registros de los partidos políticos existentes en la época. Esta fase del estudio, por tanto, nos ha permitido conocer en profundidad la evolución de la cabecera, además de averiguar la ideología que los escritores del periódico profesaban durante la transición a la democracia, lo cual constituye una de las principales líneas de esta investigación.

Una vez analizado técnicamente el periódico, procedemos a aplicar el análisis de contenido, que es la segunda fase del método aplicado en este trabajo. Se trata de un estudio sistemático, que aplicado a una muestra seleccionada objetivamente, nos permite hacer inferencias validas y confiables de acuerdo al contexto en el que los textos fueron producidos (Krippendorff, 1982: 63). Para profundizar aún más en nuestro estudio, hemos optado por el análisis de contenido explícito ya que, de acuerdo a Landry (1991: 341), éste refiere lo explícitamente dicho o escrito.

Y para que los resultados puedan ser comparados con los obtenidos en los casos de Arriba y Odiel, aumentando así el alcance de este trabajo, hemos seleccionado los mismos períodos que ya estudiamos en dichos trabajos: 20 hitos históricos ocurridos entre noviembre de 1975 y diciembre de 1978.

Una vez recopilada la muestra, compuesta por 100 ediciones publicadas por Sur entre 1975 y 1978, es momento de presentar las unidades de análisis a las que hemos aplicado el análisis de contenido. Aquéllas son segmentos del contenido caracterizados para su clasificación dentro de categorías (Berelson, 1952: 52). Considerando que nuestros objetivos persiguen, entre otras cosas, demostrar la existencia de diferentes puntos de vista ideológicos dentro de las páginas de opinión de Sur, al igual que ya 
hicimos en los casos de Arriba y Odiel, hemos optado por el análisis de los editoriales, artículos y columnas de opinión, ya que son los géneros en los que mayor pluralidad de opinión podemos encontrar, según López Hidalgo (2012: 41-42).

Tabla 1: Hitos históricos seleccionados para el estudio

\begin{tabular}{|c|c|}
\hline Gobierno & Hitos históricos \\
\hline \multirow{6}{*}{$\begin{array}{l}\text { Gobierno de Arias } \\
\text { (1975-1976, 'de } \\
\text { inmovilismo político') }\end{array}$} & Muerte de Franco (20/11/1975) \\
\hline & Instauración de la Monarquía (23/11/1975) \\
\hline & Huelga general (01/03/1976) \\
\hline & Muertes de Vitoria (03/03/1976) \\
\hline & Dimisión de Arias Navarro (02/07/1976) \\
\hline & Nombramiento de Suárez (05/07/1976) \\
\hline \multirow{7}{*}{$\begin{array}{l}\text { Gobierno de Suárez } \\
\text { (1976-1977, 'administración } \\
\text { reformista') }\end{array}$} & Referéndum de la ley para la reforma política $(15 / 12 / 1976)$ \\
\hline & Crímenes de Atocha (24/01/1977) \\
\hline & Disolución del Movimiento Nacional (01/04/1977) \\
\hline & Legalización del Partido Comunista (10/04/1977) \\
\hline & Dimisión de Pita da Veiga (11/04/1977) \\
\hline & Convocatoria electoral (12/04/1977) \\
\hline & Elecciones generales $(15 / 06 / 1977)$ \\
\hline \multirow{7}{*}{$\begin{array}{l}\text { Gobierno de la UCD } \\
\text { (1977-1978, 'Ejecutivo del } \\
\text { consenso') }\end{array}$} & Amnistía General (15/10/1977) \\
\hline & Pactos de la Moncloa (25/10/1977) \\
\hline & Regreso de Tarradellas (23/10/1977) \\
\hline & Crisis en la Comisión Constitucional (07/03/1978) \\
\hline & Aprobación de la Constitución (01/11/1978) \\
\hline & Operación Galaxia (18/11/1978) \\
\hline & Referéndum de la Constitución (06/12/1978) \\
\hline
\end{tabular}

Fuente: Elaboración propia a partir de los datos presentados por Martínez Fábregas, Jezabel y Romero Domínguez L. R. (2014).

Para el autor, los editoriales reflejan el sentir del grupo al que pertenece el medio en cuestión (López Hidalgo, 2012: 35). No es de extrañar entonces que los investigadores hayan estudiado tradicionalmente este género por el importante papel que juega en el asentamiento de un estado de opinión, ignorando así la función de las columnas 
y los artículos. Sin embargo, para Martínez Albertos (1992: 382) y Núñez Ladeveze (1995: 109), estos últimos son espacios de opinión reservados para escritores externos (sin relación contractual con el medio en cuestión, tal y como sostiene Pineda, 2006) de buena reputación, a los que se les brinda la oportunidad de interpretar y elegir libremente el tema que analizarán con la única condición de que firmen sus textos.

Es por ello que, López Hidalgo (2012: 41-42) sostiene que las variaciones entre las opiniones sostenidas por cada uno de ellos pueden ser muy destacables, ya que mientras el editorial responde a los intereses del grupo, los textos de opinión firmada gozan de independencia en el planteamiento de sus opiniones.

Y es precisamente, esta pluralidad de opinión a la que alude López Hidalgo (2012), la que validaría a artículos y columnas de opinión como garantes de la pluralidad de opinión, tal y como sostienen Borrat (1989), Gómez Calderón (2004) y Villalobos (2010).

Tomando en consideración estas ideas durante el proceso de recopilación de nuestra muestra, tenemos un total de 240 textos de opinión publicados durante los períodos seleccionados. Para su clasificación, procedemos a diseñar las categorías que nos han permitido validar o refutar nuestras hipótesis para alcanzar nuestros objetivos.

Tabla 2: Categorías (contenido cuantitativo) y subcategorías (contenido cualitativo) aplicadas a la muestra de análisis

\begin{tabular}{|c|c|c|}
\hline $\begin{array}{l}\text { Categoría } \\
\text { (Análisis de } \\
\text { contenido } \\
\text { cuantitativo) }\end{array}$ & $\begin{array}{l}\text { Código de } \\
\text { registro }\end{array}$ & $\begin{array}{c}\text { Subcategoría } \\
\text { (Análisis de contenido cualitativo) }\end{array}$ \\
\hline \multirow{2}{*}{ Posición de apoyo } & \multirow{2}{*}{$(+)$} & Alabanza a la gestión gubernamental \\
\hline & & Petición de apoyo ciudadano al Gobierno \\
\hline \multirow[b]{2}{*}{ Posición neutral } & \multirow[b]{2}{*}{$(0)$} & Ignorancia a la gestión gubernamental \\
\hline & & $\begin{array}{l}\text { Pronunciamiento sobre la gestión gubernamental a } \\
\text { título informativo, sin juicios de valor }\end{array}$ \\
\hline \multirow{2}{*}{ Posición crítica } & \multirow{2}{*}{$(-)$} & Crítica a la gestión gubernamental \\
\hline & & $\begin{array}{l}\text { Petición de retirada de apoyo ciudadano al } \\
\text { Gobierno }\end{array}$ \\
\hline
\end{tabular}

Fuente: Elaboración propia.

Categoría es, según Berelson (1952: 55), todo aquel concepto genérico en el que podemos clasificar las unidades de análisis (editoriales, artículos y columnas de opinión, en este caso). Tomando en consideración nuestras hipótesis y objetivos, nos hemos centrado 
en la tipología de dirección (que persigue la demostración de una hipótesis) propuesta por Krippendorff (1989: 406-407). Y considerando que hemos aplicado análisis de contenido tanto cuantitativo como cualitativo en este trabajo, estas son las categorías y subcategorías resultantes (Ver tabla 2).

Las categorías fijadas para el análisis de contenido cuantitativo nos han permitido confirmar si hay un discurso homogéneo, tal y como sería previsible siendo el periódico objeto de análisis parte de una cadena de medios propagandísticos (Pineda, 2006, Postoutenko, 2010), o si, por el contrario, diferentes discursos con respecto a la gestión del Gobierno coexistían dentro de las páginas de opinión del diario durante la transición española, tal y como plantea esta investigación. Y, las subcategorías nos han permitido conocer los matices existentes dentro de cada posicionamiento, demostrando la existencia de pluralismo ideológico en el diario

Durante las últimas tres décadas, los historiadores de la comunicación han sostenido que la prensa oficial mantuvo su posición de apoyo al Gobierno durante la transición a la democracia (Alférez, 1986, Montabes Pereira, 1989; Redero y Garcia, 1991- 1992). La presencia de los otros dos discursos, neutro y negativo, por lo tanto, demostraría que diferentes posiciones y opiniones con respecto a la administración central coexistieron en Sur, tal y como asumen nuestras hipótesis en el caso que nos ocupa. Algo que ya ha sido demostrado en los casos de Arriba y Odiel (Martínez Fábregas y Romero Domínguez, 2014; Martínez Fábregas, 2015). Por lo tanto, esta diversidad de opinión, de ser probada, demostraría la existencia de voces que escapan al poder autoritario, rompiendo el modelo propagandístico que plantea Pineda (2006), demostrando que la cabecera de referencia regional del Movimiento para Andalucía no fue un órgano de propaganda a disposición del Gobierno durante la transición española.

Una vez explicado el método que hemos aplicado en esta investigación, procedemos a presentar los resultados a los que hemos llegado.

\section{Resultados y discusión}

\subsection{Adaptación estructural e ideológica de Sur}

La biografía técnica aplicada a la cabecera ha demostrado que, por un lado, la mayoría de los escritores que trabajaron para Sur durante la transición fue personal externo (93\%). Gracias a esto, no debían obediencia a los dictados editoriales, al contrario que el personal propio, que sí debía comulgar en sus textos con la línea editorial del diario, debido a su relación contractual (Pineda, 2006).

El siguiente gráfico presenta el grado de apertura del diario a voces externas durante nuestro período de estudio. 
Gráfico 1: Relación contractual de escritores con Sur durante la transición

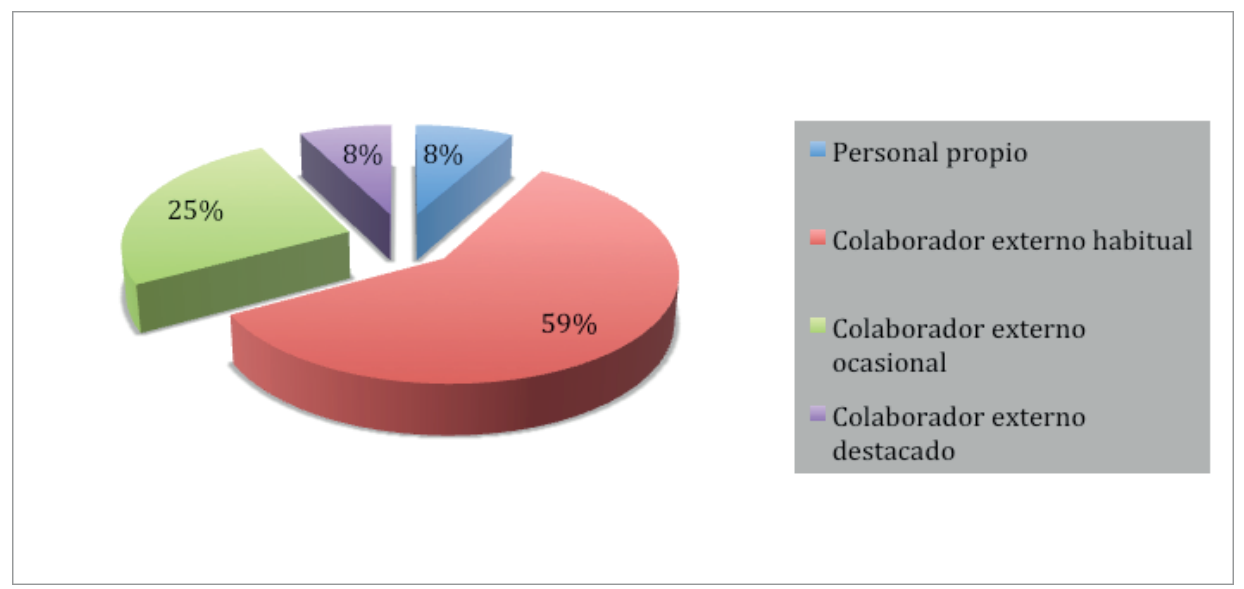

Fuente: Elaboración propia a partir de la tesis doctoral de Martínez Fábregas, J. 2014.

Los datos revelan la presencia de un extraordinario volumen de personal externo trabajando para el periódico durante la transición. En este sentido, el 59\% de los escritores era personal externo habitual, colaboradores con una relación asidua con el periódico, aunque no contractual; seguido de personal externo ocasional $(25 \%)$, que colaboraba de forma esporádica con la cabecera, sin tener relación laboral alguna; personal externo destacado (8\%), que eran colaboradores de reconocido prestigio que de forma muy inusual y destacada firmaban un texto de opinión publicado en el diario, y que solían tratar temas de política principalmente; y personal propio (8\%), que tenían relación laboral con Sur. La escasa presencia de personal propio permitía que los textos de opinión pudieran sostener puntos de vista distintos a los propuestos por los editoriales del periódico, dotando a la cabecera de pluralidad de opinión, tal y como sostenían Borrat (1989: 10) y López Hidalgo (2012: 42), entre otros.

Pero, para que hubiera pluralidad de opinión política, era necesaria, primero, la pluralidad ideológica, que también estuvo presente en la redacción durante nuestro período de estudio. El falangismo de Primo de Rivera, el nostálgico, fue la ideología con mayor representación en la redacción del periódico (40\%), seguida por el socialismo, representado por el PSOE de Felipe González, y el centrismo, representado por las fuerzas políticas más moderadas, cercanas a la CDS, y posterior UCD de Adolfo Suárez, (30\%, respectivamente), tal y como se puede comprobar en el siguiente gráfico: 
Gráfico 2: Ideologías presentes en la redacción de $S u r^{2}$

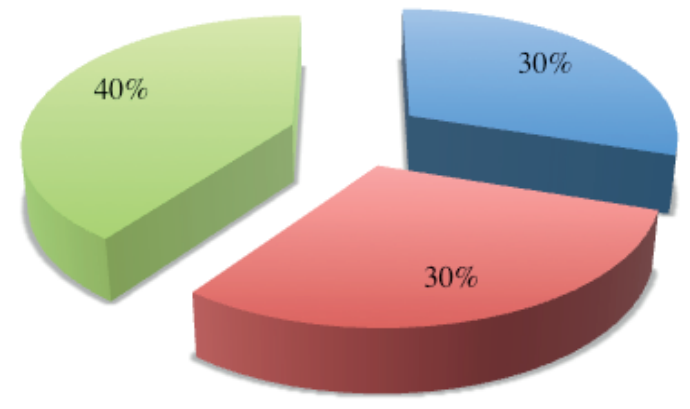

Socialismo

Ucedismo

Falangismo

Fuente: Elaboración propia a partir de los datos de la tesis doctoral de Martínez Fábregas, Jezabel. 2014.

Los datos del gráfico anterior revelan que distintas ideologías confluyeron dentro del diario Sur, tal y como asumía nuestra primera hipótesis. Esta pluralidad ideológica que confluye en el diario fue el resultado de la amplia presencia de personal externo trabajando para Sur durante el período de estudio. Debido a la ausencia de una relación contractual entre el escritor y el periódico, el primero no debía obediencia al último, tal y como reconocía Pineda (2006). De esta forma, los escritores eran libres para expresar su propio punto de vista sobre el tema que estaban analizando, con la única condición de que firmaran sus textos (Martínez Albertos, 1992: 382). Sin embargo, observamos en este sentido que Sur, aunque abrió sus páginas a distintas ideologías, intentó estar más o menos en consonancia con la sociedad española del momento que, ante el miedo a un nuevo alzamiento, apostaba por la moderación que proponían UCD y PSOE. Esto justifica la ausencia de fuerzas de extrema derecha o extrema izquierda como podían ser grupos políticos como Fuerza Nueva (derechas) o PCE (izquierdas).

Considerando lo anterior, podemos afirmar que la extraordinaria presencia de personal externo permitió la entrada de una moderada diversidad ideológica en la cabecera andaluza durante la transición a la democracia. Y esta pluralidad dotó al periódico de diversidad de opiniones sobre el proceso de transición hacia la democracia que estaba viviendo el país y la gestión que el Gobierno estaba llevando a cabo en este sentido.

${ }^{2}$ Para conocer en profundidad los datos de ideología de cada uno de los escritores que colaboraron con Sur durante la transición, puede el lector acceder a la tesis doctoral Martínez Fábregas, Jezabel (2014): La imagen del Gobierno en la prensa oficial durante la transición española (1975-1978). Análisis comparativo de Arriba, Pueblo, Solidaridad Nacional, El Pueblo Gallego, Hierro, Sur y Odiel. Universidad de Sevilla. 
Sin embargo, como parte de la estrategia de supervivencia al Franquismo puesta en marcha por el diario tras la muerte del caudillo, la cabecera malagueña no sólo evolucionó a nivel estructural e ideológico, sino también a nivel periodístico.

\subsection{Evolución periodística de la cabecera}

Saiz Cagigas estuvo a cargo de la dirección del periódico durante toda la transición. Sin embargo, opuestamente a la estabilidad que se respiraba en el sillón de la dirección del diario, el editorialismo se caracterizó durante este período por una evolución constante, experimentando considerables alteraciones. De esta forma, los editoriales no tuvieron una localización fija dentro de la cabecera durante todo el período de estudio, aunque solían aparecer en la sección de 'Nacional' y en 'Portada'. Con una frecuencia de publicación muy irregular, se publicaba en períodos que variaban entre los dos y los siete días. Sin embargo, su regularidad se incrementó considerablemente a partir de octubre de 1977, cuando alcanzó la frecuencia de publicación diaria. Desde entonces, llegaron a publicarse hasta tres textos por día.

$\mathrm{Su}$ extensión también fue muy variable, oscilando entre una columna y media página. Rara vez el editorial llegaba a tener más longitud. Cuando esto ocurría, el texto se dividía en dos páginas, empezando siempre en la portada y continuando en las páginas dos o siete, que estaban dedicadas a la opinión. Con respecto a su titulación, siempre iba en mayúsculas, sin encabezamientos identificativos ni firma.

Por otro lado, los artículos y las columnas de opinión firmada por los escritores en cadena, tales como Manuel Blanco Tobío, Fernando Ónega, Demetrio Castro Villacañas o Carlos Rodríguez, entre otros (trabajadores de la Cadena de Prensa del Movimiento), eran algunas veces editorializados, y por tanto, asumidos por el periódico como opinión propia. Normalmente, los textos de opinión firmada por estos periodistas se solían ubicar en las secciones de 'Nacional', 'Noticias de Extranjero', Opinión' y 'Contraportada', ya que eran opinión procedente de la cadena y, por tanto, oficial y propia. Por el contrario, los textos de opinión firmada por personal externo, tales como Joaquín Aguirre Bellver, Emilio de Miguel, Luis Vera, Manuel Alcántara, o Rafael Ballesteros, entre otros, eran ubicados en la sección 'Comentarios, colaboraciones y puntos de vista', que era la sección de opinión reservada para la opinión externa. En referencia a su frecuencia de publicación, hasta seis textos de opinión firmada fueron publicados a diario durante nuestro período de estudio.

La existencia de una página de opinión reservada por completo a la opinión externa, unida a la extraordinaria presencia de personal externo habitual, ocasional y destacado que hemos referido anteriormente, sugieren que el periódico confiaba a los colaboradores externos el mayor peso de la interpretación de los hechos que ocurrían en España en ese período. Considerando esto, podemos afirmar que, durante nuestro período de estudio, Sur fue el altavoz de un amplio y variado grupo de profesionales, no solo periodistas, sino también empresarios o profesores de universidad en muchas ocasiones. De esta forma, esta diversidad profesional dotó al periódico de las bases necesarias para garantizar la pluralidad de opinión, tal y como asumía nuestra primera hipótesis. Asimismo, estos cambios tanto a nivel estructural, como ideológico y periodístico, ocurridos en Sur durante la transición demuestran que el periódico evolucionó durante el cambio de 
régimen, contradiciendo así a Alférez (1986), Montabes Pereira (1989), y Redero y García (1991-1992), y validando por completo nuestra primera hipótesis.

Una vez explicada la evolución de la cabecera malagueña durante la transición en los términos anteriormente citados, procedemos a explicar el posicionamiento que las unidades de análisis seleccionadas en este estudio (editoriales, artículos y columnas) tuvieron con respecto a cada uno de los gobiernos que se sucedieron durante el cambio de régimen. Esta fase del estudio nos ha permitido encontrar, si las hubiera, diferencias entre las opiniones que cada uno de ellos sostienen. Lo que validaría, de cumplirse, nuestra segunda hipótesis, que asumía la existencia de diferentes discursos -tanto de apoyo, como neutros y críticos- con respecto a la administración central durante la transición. Esto, a su vez, descartaría a este periódico como órgano de propaganda a disposición del Ejecutivo, como ya ocurriera con los casos de Arriba y Odiel, anteriormente citados, ya que los discursos contrarios a éste no son previsibles en las páginas de la prensa oficial de un estado aún autoritario como era España durante la transición, al menos en lo que a la prensa se refiere (Guillamet, 2002).

\section{De pro- Franquista a anti- Gobierno}

Habiendo analizado la muestra total, podemos afirmar que la posición neutral con respecto a la gestión del Gobierno durante la transición alcanza el 63,08\%, seguido por la crítica $(22,39 \%)$, y el apoyo $(14,51 \%)$. Considerando estos datos, podemos aseverar que los textos de opinión publicados en la cabecera malagueña se refieren al Ejecutivo en un tono primordialmente neutro, con algunos repuntes de crítica, inesperada eso sí por proceder de un periódico oficial. Este factor también pone en evidencia la falta de apoyo a la gestión gubernamental durante la transición española por parte del periódico estudiado, ya que sólo hemos comprobado un apoyo total a la administración central en momentos puntuales -únicamente en el nombramiento de Suárez como presidente-, como se puede observar en la tabla siguiente:

Tabla 3: Posicionamiento del editorialismo y las piezas de opinión firmada con respecto al Gobierno durante la transición española (1975-1978)

\begin{tabular}{lr|r|r|r|r|r|}
\hline & \multicolumn{3}{c}{ Editorialismo } & \multicolumn{3}{c|}{ Piezas de opinión firmada } \\
\hline Fechas históricas & \multicolumn{1}{c}{$(+)$} & \multicolumn{1}{c|}{$(0)$} & $(-)$ & \multicolumn{1}{c|}{$(+)$} & \multicolumn{1}{c|}{$(0)$} & \multicolumn{1}{c|}{$(-)$} \\
\hline $\begin{array}{l}\text { Muerte de Franco } \\
\begin{array}{l}\text { Instauración de la } \\
\text { monarquía }\end{array}\end{array}$ & $0 \%$ & $100 \%$ & $0 \%$ & $20 \%$ & $55 \%$ & $25 \%$ \\
\hline \begin{tabular}{l} 
Huelga General \\
\hline
\end{tabular} & $0 \%$ & $100 \%$ & $0 \%$ & $0 \%$ & $100 \%$ & $0 \%$ \\
\hline
\end{tabular}




\begin{tabular}{|c|c|c|c|c|c|c|}
\hline Muertes de Vitoria & $0 \%$ & $100 \%$ & $0 \%$ & $0 \%$ & $100 \%$ & $0 \%$ \\
\hline Dimisión de Arias & $100 \%$ & $0 \%$ & $0 \%$ & $0 \%$ & $0 \%$ & $0 \%$ \\
\hline $\begin{array}{l}\text { Suárez, presidente del } \\
\text { Gobierno }\end{array}$ & $100 \%$ & $0 \%$ & $0 \%$ & $87,5 \%$ & $12,5 \%$ & $0 \%$ \\
\hline $\begin{array}{l}\text { Referéndum de la Ley para } \\
\text { la Reforma Política }\end{array}$ & $0 \%$ & $0 \%$ & $0 \%$ & $0 \%$ & $100 \%$ & $0 \%$ \\
\hline Crímenes de Atocha & $0 \%$ & $100 \%$ & $0 \%$ & $18,75 \%$ & $81,25 \%$ & $0 \%$ \\
\hline $\begin{array}{l}\text { Disolución del Movimiento } \\
\text { Nacional }\end{array}$ & $0 \%$ & $100 \%$ & $0 \%$ & $0 \%$ & $100 \%$ & $0 \%$ \\
\hline $\begin{array}{l}\text { Legalización del Partido } \\
\text { Comunista }\end{array}$ & $100 \%$ & $0 \%$ & $0 \%$ & $0 \%$ & $100 \%$ & $0 \%$ \\
\hline $\begin{array}{l}\text { Dimisión } \\
\text { de Pita da Veiga }\end{array}$ & $0 \%$ & $0 \%$ & $0 \%$ & $0 \%$ & $100 \%$ & $0 \%$ \\
\hline Convocatoria electoral & $0 \%$ & $0 \%$ & $0 \%$ & $0 \%$ & $0 \%$ & $100 \%$ \\
\hline Elecciones Generales & $0 \%$ & $100 \%$ & $0 \%$ & $12,5 \%$ & $45 \%$ & $42,5 \%$ \\
\hline Amnistía General & $0 \%$ & $33,33 \%$ & $66,66 \%$ & $0 \%$ & $100 \%$ & $0 \%$ \\
\hline Pactos en la Moncloa & $0 \%$ & $20 \%$ & $80 \%$ & $0 \%$ & $100 \%$ & $0 \%$ \\
\hline Regreso de Tarradellas & $0 \%$ & $0 \%$ & $0 \%$ & $0 \%$ & $100 \%$ & $0 \%$ \\
\hline $\begin{array}{l}\text { Crisis de la Comisión } \\
\text { Constitucional }\end{array}$ & $0 \%$ & $0 \%$ & $0 \%$ & $0 \%$ & $100 \%$ & $0 \%$ \\
\hline $\begin{array}{l}\text { Aprobación de la } \\
\text { Constitución }\end{array}$ & $0 \%$ & $100 \%$ & $0 \%$ & $0 \%$ & $100 \%$ & $0 \%$ \\
\hline Operación Galaxia & $0 \%$ & $0 \%$ & $0 \%$ & $0 \%$ & $100 \%$ & $0 \%$ \\
\hline $\begin{array}{l}\text { Referéndum de la } \\
\text { Constitución }\end{array}$ & $0 \%$ & $50 \%$ & $50 \%$ & $0 \%$ & $66,66 \%$ & $33,33 \%$ \\
\hline Total & $13,04 \%$ & $56,52 \%$ & $30,43 \%$ & $7,30 \%$ & $76,86 \%$ & $15,83 \%$ \\
\hline
\end{tabular}

Fuente: Tabla elaborada a partir de los datos de la tesis doctoral de Martínez Fábregas, Jezabel. 2014. Anexos, p. 173. 
Estos datos revelan que las posiciones categorizadas (de apoyo, neutra y crítica) están representadas en los textos de opinión firmada publicados en Sur durante las fechas históricas analizadas. Sin embargo, el tono neutral es la tónica general. Así, la posición de apoyo y la críticas con respecto al Ejecutivo únicamente destacaron en momentos puntuales. De esta forma, únicamente la dimisión de Arias Navarro y el nombramiento de Suárez como presidente del Gobierno fueron interpretados por la opinión del periódico como una buena gestión por parte del Ejecutivo. Por el contrario, durante hechos históricos como la muerte de Franco, la huelga general, la Amnistía General, los Pactos de la Moncloa y el referéndum de la Constitución, el papel jugado por la Administración central fue duramente criticado desde las piezas de opinión firmada publicadas en el diario.

La existencia de diferentes posiciones con respecto al Ejecutivo, por tanto, pone en evidencia, a nivel cuantitativo, la presencia de pluralismo discursivo y de opinión dentro del periódico de referencia regional del Movimiento para Andalucía durante la transición española. Este comportamiento no es sólo inesperado sino también inadmisible por parte de un periódico oficial que había sido engendrado como un órgano de propaganda a disposición del régimen franquista.

En consecuencia, la ausencia de un discurso único y homogéneo destaca en la línea editorial, y más aún en las piezas de opinión firmada. De esta forma, los editoriales optaban, en algunas ocasiones, por ignorar el papel jugado por el Gobierno, y otras, por criticarlo o apoyarlo. Además, había momentos puntuales en los que ignoraban completamente las acciones políticas acometidas por el mismo.

Las piezas de opinión firmada, por su parte, mantuvieron una posición neutral con respecto a la Administración. Sin embargo, las posiciones críticas alcanzan un porcentaje considerable $(15,83 \%)$. En consecuencia, la posición de apoyo total con respecto a la administración central fue del $10,17 \%$, lo que sorprende tratándose de un periódico oficial engendrado durante la dictadura como órgano de propaganda del régimen.

A continuación explicamos a nivel cualitativo el posicionamiento que los editoriales y las piezas de opinión firmada mantuvieron con respecto a cada uno de los Gobiernos que se sucedieron durante la transición.

\section{De la alabanza a la crítica del inmovilismo durante el Gobierno de Arias (1975-1976)}

La línea editorial mostró su aflicción por la muerte de Franco, destacando el profundo pesar que dicha pérdida había traído al corazón de los españoles ${ }^{3}$. Y, mientras el editorial ignoró a la Administración central, Ónega aprovechó la oportunidad para responsabilizarla de la constante inflación reinante en el país ${ }^{4}$.

\footnotetext{
${ }^{3}$ Sur, 20/11/1975, p. 3: DOLOR DE ESPAÑA.

${ }^{4}$ Sur, 20/11/1975, Fernando Ónega, El Péndulo.
} 
Unos días más tarde, Juan Carlos I juró su cargo como rey de España, lo que supuso la instauración de la monarquía. Este hecho fue considerado como el nexo de unión para los españoles, separados hasta entonces por el tradicional 'vencedores y vencidos' de la Guerra Civil, ya que el nuevo monarca no había vivido la contienda en primera persona ${ }^{5}$. El editorial ignoró entonces el papel jugado por el Gobierno. De la misma forma, los textos de opinión firmada se centraron en el personaje del rey de España, considerándolo como un 'hombre de pulso' que llevaría al país a la democracia, erradicando la inestabilidad existente en el país ${ }^{6}$, y pasando por alto la gestión gubernamental. Del Solar Ordoñez, sin embargo, fue el único que se refirió al papel jugado por el Gobierno en este hecho histórico, alabando su gestión en la puesta en marcha de las bases institucionales que debían allanar el camino para el advenimiento de la democracia? .

La huelga general, sin embargo, rompió la calma reinante en el periódico, desencadenando una pluralidad de posiciones con respecto a la gestión gubernamental. Por un lado, los editoriales acusaron al Partido Comunista de instigar la huelga a través del pago de 6.000 pesetas a los militantes que organizaran un paro en el trabajo. Y, por otro lado, criticaban al Ejecutivo por el libertinaje político existente en el país desde la desaparición del Caudillo ${ }^{8}$, acusándole de falta de autoridad ${ }^{9}$.

Las críticas contra la administración central también aumentaron en las piezas de opinión firmada. De esta forma, Cristóbal Páez exigió la puesta en marcha de políticas reformistas para salir de la crisis económica en la que se encontraba inmerso el país desde $1975^{10}$, y que fue el resultado, a juicio de Fernando Ónega, de la falta de autoridad del Gobierno Arias ${ }^{11}$. El autor incluso llegó a exigir la dimisión de Arias como presidente del Gobierno español, considerándolo como un anclaje al Franquismo que impedía el avance hacia la democracia ${ }^{12}$.

La reacción por parte del presidente a esta demanda no se hizo esperar. Así, como resultado de las constantes disensiones entre Arias y el Rey Juan Carlos I (Zugasti, 2005: 145), el primero abandonó su cargo como Jefe de Gobierno en julio de 1976. Su salida de la administración pasó casi desapercibida por el periódico. Sólo un editorial agradeció a Arias su espíritu democrático en la gestión política del país hasta entonces ${ }^{13}$. Dos días más tarde, Suárez fue nombrado presidente del Gobierno, hecho que fue muy aplaudido por parte de los textos de opinión publicados en Sur. De esta forma, los

\footnotetext{
${ }^{5}$ Sur, 22/11/1975, p. 3: EL REY, SÍMBOLO DE LA UNIDAD.

${ }^{6}$ Sur, 23/11/1975, p. 25. Joaquín Aguirre Bellver, España, con pulso.

${ }^{7}$ Sur, 20/11/1975, p. 7 (Juan José del Solar Ordóñez), Las Instituciones.

${ }^{8}$ Sur, 04/03/1976, p. 28: SEIS MIL PESETAS DIARIAS POR HUELGA.

${ }^{9}$ Sur, 5/3/1976, p. 1: PROFESIONALES DE LA AGITACIÓN.

${ }^{10}$ Sur, 3/3/1976, p. 29. Cristóbal Páez, El observatorio.

${ }^{11}$ Sur, 6/3/1976, pp. 1 y 28. Fernando Ónega, El Péndulo.

${ }^{12}$ Sur, 4/3/1976, p. 44. Fernando Ónega, El Péndulo.

${ }^{13}$ Sur, 2/7/1976, p. 40: En la hora de un relevo.
} 
editoriales mostraron su confianza en él ${ }^{14}$. Los textos de opinión firmada, por su parte, consideraron este cambio de Gobierno como la evidencia de la superación del tópico 'vencedores y vencidos' reinante en España desde la Guerra Civil, ya que Suárez, al igual que el rey, no había vivido la contienda de primera mano ${ }^{15}$. En la misma línea, Blanco Tobío consideró al nuevo presidente como el eje de la transición, asegurando que traería la democracia al país ${ }^{16}$.

Considerando lo anterior, podemos decir que la controversia fue la protagonista de los textos de opinión firmada publicados en Sur durante la primera fase de nuestro período de estudio. De esta forma, las críticas y las alabanzas al Gobierno fluían en las páginas de opinión del periódico, contradiciendo así a Redero y García (1991-1992), quien afirmaba que la prensa oficial fue un órgano de propaganda a disposición del Gobierno de Arias Navarro.

Una vez Suárez asentado en el poder, comenzaba el período reformista en el país.

\section{Del agradecimiento a la crítica}

por la proximidad ideológica del Gobierno Suárez al franquismo (1976-1977)

A pesar de que Sur recibió de buena gana a Suárez como presidente del Gobierno, la primera medida política que acometió, el referéndum para la Ley de la Reforma Política, no despertó gran entusiasmo en la línea editorial. Por el contrario, las piezas de opinión firmada sí tomaron parte en el análisis de este hecho histórico. Así, Francisco Torres Prado pidió el 'si' en la consulta, considerándola un primer paso para alcanzar la democracia ${ }^{17}$. De la misma forma, Emilio de Miguel consideró el 'sî' como un paso hacia delante en la consecución del ansiado consenso político ${ }^{18}$.

A principios de 1977, los crímenes de Atocha desencadenaron aún mayor controversia. Los editoriales apelaron entonces a la unidad de los españoles, exigiendo al Gobierno que uniera fuerzas con la -aún ilegal- oposición, tanto de derechas como de izquierdas, para preservar las libertades públicas existentes en el país ${ }^{19}$. Torres Prados, sin embargo, reconoció las dificultades a las que el Ejecutivo tenía que hacer frente a diario (ataques terroristas, secuestros, etc.), pidiendo a los españoles solidaridad y colaboración, a la vez que recomendaba al Gobierno trabajar con autoridad y flexibilidad ${ }^{20}$.

En abril de ese mismo año, la disolución del Movimiento Nacional fue aplaudida por la cabecera andaluza, tanto por los editoriales como por los textos de opinión firmada, que consideraban esta acción política como el punto de inicio para la 'nueva

\footnotetext{
${ }^{14}$ Sur, 4/7/1976, p. 32: A.S.

${ }^{15}$ Sur, 4/7/1976, p. 32: A.S.

${ }^{16}$ Sur, 4/7/1976, pp. 1 y 30. Manuel Blanco Tobío, Un hombre para este tiempo.

${ }^{17}$ Sur, 14/12/1976, p. 7. Francisco de la Torre Prados, Democracia ¿para qué?

${ }^{18}$ Sur, 17/12/1976, p. 27. Emilio de Miguel, La abstención.

${ }^{19}$ Sur, 29/1/1977, p. 1: POR LA UNIDAD DE TODOS.

${ }^{20}$ Sur, 29/1/1977, p. 7. Francisco de la Torre Prados, Parar la violencia.
} 
España ${ }^{21}$, sin juzgar el papel que jugó en ella la administración central. De igual forma, la legalización del Partido Comunista fue recibida de muy buena gana y considerada como una decisión correcta por parte del Ejecutivo, "que estaba demostrando su espíritu democrático"22.

La dimisión de Pita da Veiga como ministro de Marina -la consecuencia directa de la legalización del PC- y la convocatoria de las elecciones legislativas fijadas para junio de 1977 no fueron interpretadas por los editoriales de la cabecera malagueña. Sin embargo, mientras las piezas de opinión siguieron la línea marcada por el editorial con respecto a la dimisión de Pita da Veiga - no abordaron el hecho-, la convocatoria electoral sí llamó su atención. De esta forma, Castro Villacañas acusó al Ejecutivo de aproximarse constantemente a la oposición de derechas, proponiendo un Gobierno de centro-izquierda para la llegada de la democracia ${ }^{23}$.

Ya inmerso en las elecciones de junio de 1977, el editorialismo pidió el voto para UCD, ya que era la opción política moderada del momento ${ }^{24}$. También destacó el espíritu de armonía y serenidad del Gobierno ${ }^{25}$, destacando y agradeciéndole la pluralidad política que concurría a las primeras elecciones democráticas celebradas en España desde $1936^{26}$.

Más diversas, sin embargo, fueron las posiciones asumidas por las piezas de opinión firmada. Por un lado, José Cavero exigió a la Administración central que sentara las bases que garantizaran la justicia electoral, ya que consideraba que Suárez, siendo el 'presidente-candidato', tenía más oportunidades de ganar las elecciones que el resto de sus oponentes ${ }^{27}$. También aprovechó la oportunidad para criticar al presidente, a quien consideró un producto del régimen franquista ${ }^{28}$. En la misma línea, Marco criticó los constantes acercamientos de la UCD (dirigida por Adolfo Suárez) a Alianza Popular ${ }^{29}$. Y, por otro lado, Salcedo pidió al pueblo que confiara en la UCD, considerándolo como la mejor opción política existente en el país ${ }^{30}$. En la misma línea, José Luís Casas, un preso político durante la dictadura, destacó que los españoles le debían a Suárez, y por lo tanto, al Ejecutivo, los primeros pasos hacia la democracia, pidiendo por ello el voto para UCD como recompensa y garantía de una buena gestión política ${ }^{31}$.

\footnotetext{
${ }^{21}$ Sur, 2/4/1977, pp. 1 y 44. EL ÚLTIMO SERVICIO.

${ }^{22}$ Sur, 10/4/1977, p. 39: Editorial del diario $<<$ Arriba $>>$.

${ }^{23}$ Sur, 13/4/1977, p. 29. Demetrio Castro Villacañas, Atención al Centro.

${ }^{24}$ Sur, 8/6/1977, p. 32. MODERACIÓN.

${ }^{25}$ Sur, 12/6/1977, p. 63: PROGRAMA Y ACTITUDES ELECTORALES.

${ }^{26}$ Sur, 15/6/1977, p. 1: El espíritu del 15 de junio.

${ }^{27}$ Sur, 10/6/1977, p. 33. José Cavero, El presidente candidato.

${ }^{28}$ Sur, 12/6/1977, p. 7. A.P.L, El respeto mutuo, base firme de una democracia en orden.

${ }^{29}$ Sur, 10/6/1977, p. 7. Marco, EN VÍSPERA DE LAS ELECCIONES, Precisando.

${ }^{30}$ Sur, 10/6/1977, p. 33. Antonio Salcedo, LA SITUACIÓN, Programas.

${ }^{31}$ Sur, 11/6/1977, p. 30. José Luis Casas, Más difícil todavía.
} 
Como hemos comprobado, el Gobierno de Suárez fue considerado tanto democrático como anti-democrático por los textos de opinión firmada publicados en Sur. Esto demuestra la falta de un discurso único en defensa de las acciones políticas llevadas a cabo por el Ejecutivo. Manifiesta, a su vez, una pluralidad discursiva con respecto a la gestión llevada a cabo por el gobierno Suárez dentro de las páginas de opinión de la cabecera regional, lo que contradice a Alférez (1986) y a Montabes Pereira (1989), quienes consideraban que la prensa oficial fue un órgano de propaganda a disposición del Gobierno durante la transición a la democracia.

Así fue como, con la llegada de UCD al Ejecutivo a mediados de 1977, comenzó el Gobierno del consenso.

\section{Crítica a la traición del Gobierno de la UCD a la democracia (1977-1978)}

Una vez asentado en el Gobierno, UCD aprobó la Amnistía General en octubre de 1977, lo que desencadenó la defensa del Ejecutivo en el editorialismo de Sur ${ }^{32}$. Consideró la medida como un triunfo de la libertad ${ }^{33}$. Las piezas de opinión firmada, sin embargo, optaron por ignorar el rol jugado por el Ejecutivo en esta acción política. Y, mientras los editoriales ignoraron el regreso de Tarradellas, presidente de la Generalitat de Catalunya, del exilio, las piezas de opinión firmada aprovecharon el revuelo para demandar la puesta en marcha del proceso autonómico en Andalucía ${ }^{34}$.

Los Pactos de la Moncloa marcaron un punto de inflexión en la posición de este periódico con respecto al Gobierno. Durante la negociación de estos acuerdos económicos, la UCD propuso el cierre definitivo de los MCSE (Medios de Comunicación Social del Estado) -cadena estatal a la que pertenecía Sur-, considerando que no tenía lugar en un estado democrático. Con respecto a esta propuesta, el editorialismo acusó a la administración de aprovecharse de la prensa oficial durante la campaña electoral para alcanzar el Gobierno, para posteriormente abandonarla a su suerte ${ }^{35}$. Las piezas de opinión firmada también reaccionaron críticamente a la propuesta gubernamental, recordándole al Ejecutivo que "ser prensa estatal no significa ser antidemocrática, a menos que el estado en el que estamos sea autoritario"36. También acusó al gabinete gubernamental de estar retrasando el proceso autonómico en Andalucía para dar cumplimiento a la 'unidad de España' que tanto defendió Franco, considerándolo así como un anclaje que impedía el avance del país hacia la democracia ${ }^{37}$.

${ }^{32}$ Sur, 9/10/1977, p. 49. ESOS HOMBRES QUE MUEREN.

${ }^{33}$ Sur, 15/10/1977, p. 37. UN TRIUNFO DE LA LIBERTAD.

${ }^{34}$ Sur, 15/10/1977, p. 7. Manuel Téllez Laguna, ¿Tendremos autonomía?

${ }^{35}$ Sur, 19/10/1977, p. 56. PRENSA DEL ESTADO I. Ética social, trabajo y profesión. Sur, 20/10/1977, p. 56. PRENSA DEL ESTADO II. Periódicos institucionales y democracia.

${ }^{36}$ Sur, 27/10/1977, p. 40. Manuel Blanco Tobío, PRENSA DEL ESTADO.

${ }^{37}$ Sur, 28/10/1977, p. 7. Carlos Guirado Arrabal, La autogestión de la autonomía de Andalucía. 
Y en este ambiente controvertido, llegamos a 1978. El año que culminó con el referéndum de la Constitución empezó con la lucha por alcanzar el consenso. Sin embargo, no fue una tarea fácil.En marzo, el PSOE abandona la Comisión Constitucional a cargo de la redacción de la Carta Magna. Este hecho fue completamente ignorado tanto por los editoriales como por las piezas de opinión firmada publicados en el periódico.

Por el contrario, la aprobación de la Constitución fue extensamente analizada por columnas y artículos, aunque no por los editoriales. De esta forma, Javier Huellín destacó los beneficios que la Constitución traería al país ${ }^{38}$. Sin embargo, quedaba aún un largo y arduo camino por recorrer.

Mediados de noviembre de 1978, la Operación Galaxia -el intento de Golpe de Estado ocurrido durante la transición-, dio el primer susto a la naciente democracia. Es digno de mención el hecho de que tanto los editoriales como los textos de opinión firmada optaron por ignorar este asunto, evitando así la crispación social que podía traducirse en el 'no' al referéndum cuya celebración se produciría semanas después.

Diciembre de 1978: el referéndum de la Constitución llamó poderosamente la atención de la línea editorial de Sur, que recordó a los españoles su responsabilidad política en la consulta ${ }^{39}$.

Los textos de opinión firmada, por su parte, proveyeron nuevamente de pluralidad discursiva y de opinión a las páginas de opinión de la cabecera. Así, Juan Peralta expresó su rechazo a la Constitución, a la que consideraba como una maniobra engañosa por parte del Gobierno que era impropia de un proceso democrático ${ }^{40}$. Y, E.G.N., por su parte, pidió al Ejecutivo que se pusiera a trabajar inmediatamente para resolver los problemas que afectaban al país durante ese período ${ }^{41}$. Rafael Ballesteros fue incluso más allá, recordando a Suárez que debía convocar elecciones generales tan pronto como la Constitución fuera aprobada, aprovechando la oportunidad para acusarlo a él y a su Gabinete de retrasar el proceso democrático en beneficio propio ${ }^{42}$. Carlos Rodríguez también exigió una convocatoria de elecciones generales una vez que el referéndum hubiera pasado, y aprovechó la oportunidad para proponer al PSOE como victorioso en esas elecciones, ya que consideraba que la UCD era un "gobierno antidemocrático que regía al país más en pro de sus intereses partidistas que centrándose en las necesidades del país y sus ciudadanos" ${ }^{43}$. Así, al final de nuestro período de análisis varios autores pedían la celebración de elecciones generales, a la vez que criticaban al Gobierno de la UCD de forma constante, lo que era inesperado siendo un órgano de propaganda del Gobierno, al igual que ocurriera en los casos de Arriba y Odiel (Martínez Fábregas y Romero Domínguez, 2014, y Martínez Fábregas, 2015).

\footnotetext{
${ }^{38}$ Sur, 21/11/1978, p. 11. Ignacio Javier Huelín Vallejo, Mi voto a la constitución (IV).

${ }^{39}$ Sur, 6/12/1978, p. 28. EL DEBER DE VOTAR.

${ }^{40}$ Sur, 2/12/1978, p. 7. Juan Peralta, Mis razones para votar No.

${ }^{41}$ Sur, 7/12/1978, p. 44, E.G.N., Gobernar.

${ }^{42}$ Sur, 3/12/1978, p. 7. Rafael Ballesteros, El sí de los socialistas.

${ }^{43}$ Sur, 07/12/1978, p. 3. Carlos Rodríguez, La Política y los días.
} 
Considerando la posición con respecto al Gobierno que Sur mantuvo durante la transición, podemos afirmar que la estrategia de supervivencia que puso en marcha desde el principio del período de estudio, cuando retiró el yugo y las flechas de su cabecera como símbolo de su alejamiento del Franquismo, le sirvió para abandonar su función propagandística, contradiciendo a Montabes Pereira (1989).

Por otro lado, la apertura de sus páginas de opinión a diferentes ideologías permitió la presencia de diversas interpretaciones de la gestión gubernamental, tal y como asumía nuestra primera hipótesis, y contradiciendo así a Alférez (1986). Y esto, unido a la perdida del soporte institucional que le proveía el Movimiento Nacional a raíz de su disolución en abril de 1977, lo llevaron a evolucionar, pasando de ser un periódico pro- franquista a anti-Gobierno, llegando a pedir la llegada del PSOE al Ejecutivo. Este hecho, evidencia el abandono de la función de propaganda que el diario había mantenido durante el régimen franquista, y la asunción de su rol como agente político durante la transición, validando así nuestra segunda hipótesis.

Estos resultados, por lo tanto, contradicen a Alferez (1986), Montabes Pereira (1989) y Redero y Garcia (1991), quienes afirmaban que la prensa oficial había mantenido su función propagandística durante la transición. De hecho, la cabecera malagueña no solo abrazó diferentes ideologías con respecto al Gobierno, sino que también abandonó su función propagandística, asumiendo su rol como agente político.

En la misma línea, esta investigación valida las teorías de Meneses (2008) y Castro Torres (2010), quienes afirmaban que la prensa oficial dio la bienvenida a diferentes ideologías y discursos durante la transición. Y demuestra que las piezas de opinión firmada fueron las garantes de la diversidad de opinión, tal y como apuntaban Borrat (1989) y López Hidalgo (2012). En esta línea, esta investigación va incluso más allá, demostrando que el periódico regional para la prensa del Movimiento, al igual que hicieron Arriba y Odiel (Martínez Fábregas y Romero Domínguez, 2014; Martínez Fábregas, 2015), desafió los principios de la propaganda, contradiciendo los intereses partidistas del gabinete de turno, ganando así la confianza de los lectores, y sobreviviendo en el competitivo mercado periodístico existente en ese momento en España. Por lo tanto, podemos afirmar que esta cabecera profesó una idea de periodismo como negocio y no como órgano de propaganda al servicio del Gobierno.

Una vez expuestos los resultados, procedemos a presentar las conclusiones que hemos alcanzado en este estudio.

\section{Conclusiones}

El periódico de referencia regional para la Prensa del Movimiento en Andalucía, Sur, evolucionó considerablemente, tanto a nivel ideológico como estructural durante la transición española. Por un lado, corrientes ideológicas nostálgicas (Falangista), moderadas (CDS y UCD), y progresistas (PSOE), se dieron cita en las redacciones del periódico. Esta pluralidad ideológica, unida al elevado número de colaboradores externos trabajando para el diario durante este período, son muestra de su comportamiento corporativo y empresarial, y de que pretendía alejarse de su función propagandística y hacerse un hueco en el mercado periodístico. Precisamente, este comportamiento lo 
llevó a mantenerse a flote gracias a la sinergia creada entre los trabajadores de Sur y los empresarios locales de Málaga en 1984.

Esta evolución también vino acompañada, a nivel de contenido, por la neutralización de los discursos concernientes a la gestión del Gobierno durante la transición, así como el incremento de las posiciones críticas hacia el mismo en detrimento de las de apoyo, lo que provocó la existencia de importantes contradicciones discursivas dentro de la cabecera regional. Estas disensiones permitieron que expresiones como "el Ejecutivo que está demostrando su espíritu democrático" y "el gobierno antidemocrático que rige el país más en pro de sus intereses partidistas que centrándose en las necesidades del país y sus ciudadanos" en referencia al Gobierno de la UCD, concurrieran dentro del mismo periódico, con la consecuente falta de un discurso único y homogéneo, tal y como cabría esperar de un órgano de propaganda. Este hecho demuestra que columnistas y articulistas habían asumido su rol como agentes políticos en el proceso democratizador.

En otro orden de cosas, hemos observado también un extraordinario incremento en las demandas de la puesta en marcha del proceso de autonomía para Andalucía por parte de las piezas de opinión firmada durante nuestro período de estudio. Este comportamiento demuestra una clara posición regionalista por parte de los escritores que trabajaban para el periódico analizado, sobre todo de Rafael Ballesteros, quien ondeaba la bandera regionalista de forma constante.

Por lo tanto, los resultados de este estudio demuestran la presencia de diferentes ideologías dentro del periódico analizado, lo que se tradujo en pluralismo discursivo y de opinión con respecto al Gobierno y su gestión política de la transición española, no manteniendo una línea discursiva única. Este hecho contribuyó a que la crítica contra el Ejecutivo aumentara considerablemente, llegando incluso a proponer al PSOE como la mejor alternativa a UCD de cara a los próximos comicios generales. Y este comportamiento era completamente inesperado viniendo de un órgano de propaganda, lo que demuestra que la cabecera había asumido su rol como agente político en el panorama periodístico español del momento, ocupando su puesto en el llamado 'Parlamento de Papel'.

Para concluir, este estudio enlaza con los resultados ya presentados por otros trabajos centrados en los casos de Arriba y Odiel. Ambos coinciden en que la prensa oficial, antigua prensa del movimiento, no fue un órgano de propaganda del Gobierno durante la transición; lo que contradice a las teorías defendidas por varios autores a lo largo de los últimos tres decenios. Este hecho plantea, por tanto, la necesidad de un revisionismo de la bibliografía sobre la prensa oficial durante el cambio de régimen y el papel que verdaderamente jugó en el cambio político.

\section{Bibliografía}

Alférez, A. (1986): Cuarto poder en España: la prensa desde la Ley Fraga 1966, Espulgues de Llobregat, Plaza \& Janés.

Barrera, C. (1995): Sin mordaza: veinte años de prensa en democracia, Madrid, Temas de hoy. 
Berelson, B. (1952): Content Analysis En: Handbook of Social Psychology, Vol I. Nueva-York.

Borrat, H. (1989): El periódico actor político, Barcelona, Gustavo Gili.

Casasús Guri, José María (1985): Ideologías y análisis de medios de comunicación, Barcelona, Mitre.

Castro Torres, C. (2010): La Prensa en la transición española 1966/1982, Madrid, Alianza Ensayo.

Gómez Calderón, B. (2004): "De la intellectio a la elocutio: un modelo de análisis retórico para la columna personal", Revista Latina de comunicación social, (57), p. 11.

Guillamet, J. (2002): "Factores de progreso y atraso en la evolución histórica del periodismo. El franquismo", en García Galindo, J. A., J. Gutiérrez Lozano e I. Sánchez Alarcón (eds.). La comunicación social durante el franquismo, Málaga, Centro de Ediciones de la Diputación Provincial de Málaga.

Jackall, R. (1995): Propaganda. Main trends of the Modern World, New York, University Press

Krippendorff, K. (1989): Content Analysis; An Introduction to its Methodology, Thousand Oaks, CA: Sage.

Landry, R. (1998): "L'analyse de contenu", en B. Gauthier (ed.), Recherche Sociale. De la problemátique à la collecte des données, Sillery, Presses de l'Université du Québec, p. 329-356.

López Hidalgo, A. (2012): La columna: periodismo y literatura en un género plural, Zamora, Comunicación Social.

López de Zuazo Algar, A. (1981): Catálogo de periodistas españoles del siglo XX, Madrid, Universidad Complutense.

Martín de la Guardia, R.M. (2000): "Los últimos intentos reformadores de la prensa del movimiento (1975-1976)", Revista Latina de Comunicación Social, núm. 32. 6.

Martín Vivaldi, G. (1987): Géneros periodísticos, Madrid, Paraninfo.

Martínez Albertos, J.L. (1992): Curso General de Redacción Periodística, Edición revisada, Madrid, Paraninfo/Thomson Learning

Martínez Fábregas, J. (2015): "El comportamiento de la prensa oficial con respecto al gobierno Suárez durante las elecciones legislativas de junio de 1977", Estudios sobre el Mensaje Periodístico, 21 (1), pp. 115-130.

Martínez Fábregas, J. (2015): "Structural and ideological change in the oficial press during the Spanish Transition (1975-1978)2, Revista Internacional de Historia de la Comunicación, 4 (1), pp. 153-174.

Martínez Fábregas, J. (2015): "Propaganda and counterpropaganda in the official press during the Spanish Transition (1975-1978). Arriba vs. Odiel”, Ámbitos, Revista Internacional de Comunicación, 28. Edición online.

Martínez Fábregas, J. (2014): La imagen del Gobierno en la prensa oficial durante la transición espanyola (1975-1978), en Ruiz Acosta, M.J., L. Romero Domínguez, y J. Guillamet i Lloveras (dirs.), Análisis comparativo de Arriba, Pueblo, Solidaridad Nacional, El Pueblo Gallego, Hierro, Sur y Odiel. Universidad de Sevilla. 
Martínez Fábregas, J. y L.R. Romero Domínguez (2014): “Arriba durante la Transición española: el abandono de su función propagandística con respecto al Gobierno", Historia y Comunicación Social, 19, 321-340.

Mauri de los Ríos, M. (2010): Funció i evolució de la prensa de Barcelona durant la transició democrática (1975-1978), Tesis Doctoral, Barcelona, Universitat Pompeu Fabra.

Meneses, D. (2008): Noticias sobre la prensa: imagen propia en la transición democrática, Madrid, Fragua.

Montabes Pereira, J. (1989): La prensa del estado durante la transición política español, Madrid, Siglo XXI de España de Editores.

Palacio, L. (2006): "Radiografía de los grupos de comunicación", en Tendencias 06, Medios de comunicación: el año de la televisión (pp. 419-438), Madrid, Fundación Telefónica.

Peña Marín, C. (1980): El discurso político en la prensa madrileña del franquismo, Madrid, Bulzoni.

Pineda Cachero, A. (2006): Elementos para una teoría comunicacional de la propaganda, Sevilla, Ediciones Alfar.

Postoutenko, K. J. (2010): Soviet culture: codes and messages, Bielfeld, Verlag Otto Sagner.

Redero San Román, M. y G. García González (1991-1992): Prensa y opinión pública en la transición política española, en AAVV Anales de la Universidad de Alicante, Alicante, Universitat d' Alacant.

Ruiz Romero, M. (1998): "La prensa de Andalucía durante la transición", Ámbitos, Revista Andaluza de Comunicación. Núm. 1. Disponible en: http://www.ull.es/publicaciones/latina/ambitos/1/100bruiz.htm

Soto, Á. (1994): "De las Cortes orgánicas a las Cortes democráticas", en Redero San Román, M. (1994), La transición a la democracia en España (Vol. 15), Madrid, Marcial Pons.

Tusell, J. y Á. Soto (1996): Historia de la transición, 1975-1986, Madrid, Alianza Universidad.

Villalobos Salas, C. (2010): "El articulismo de opinión como fuente para la investigación histórica: el ejemplo del franquismo", Espéculo: Revista de Estudios Literarios, 47, p. 29.

Winner, R y J. Dominick (2006): Introducción a la investigación de medios masivos de comunicación, México, Thomson Editores.

Zalbidea Bengoa, B. (1996): Prensa del movimiento en España: 1936-1983, Tesis Doctoral, Universidad del País Vasco.

Zugasti, R. (2005): "La prensa de la transición como cómplice de Juan Carlos I: el ejemplo de la legitimidad franquista de la Monarquía", Espacio Tiempo y Forma. Serie V, Historia Contemporánea, 18. 